\title{
An Information System Design for Organizational Creativity Support
}

\author{
Celina M. Olszak \\ University of Economics in \\ Katowice \\ celina.olszak@ue.katowice.pl
}

\author{
Tomasz Bartuś \\ University of Economics in \\ Katowice \\ tomasz.bartus@ue.katowice.pl
}

\author{
Pawel Lorek \\ University of Economics in \\ Katowice \\ pawel.lorek@ue.katowice.pl
}

\begin{abstract}
The aim of this paper is to explore the issue of organizational creativity support and to propose a conceptual framework for the design of an organizational creativity support system. In order to achieve the research goal, the logic of the discourse is as follows. At the start, a critical review of the relevant literature is conducted to identify the issue of computer organizational creativity support. Next, a multi-agent approach is described as a foundation for the design of the organizational creativity support system. Then, a comprehensive framework for the design of information systems to support organizational creativity is proposed. Finally, the idea of organizational creativity support system based on different intelligent agents is discussed. In conclusion, theoretical contributions and practical implications of the study are presented.
\end{abstract}

\section{Introduction}

Organizational creativity is considered one of the most developing research areas and a main vehicle of organizational development as well as the basis for staying on the market and innovative success [1], [2], [3]. Organizations that support organizational creativity and adopt the innovative practices, products and services increase their capability to be more competitive.

In previous years, some research studies have been conducted that concern IT-based creativity. However, they are fragmentary, scattered and do not refer to the essence of the organizational creativity support. They do not explain how to design organizational creativity support system [4], [5].

The aim of this paper is to explore the issue of organizational creativity support and to propose a conceptual framework for the design of an organizational creativity support system. While writing this paper the following research methods are used: critical analysis of the literature, deduction and scientific reflection as well as computer simulations. In order to achieve the research goal, the logic of the discourse is as follows. At the start, a critical review of the relevant literature is conducted to identify the ITbased organizational creativity support. Next, a multiagent approach is described as a foundation for the design of the organizational creativity support system. Then, a comprehensive framework for the design of information systems to support organizational creativity is proposed. Finally, the idea of organizational creativity support system based on different intelligent agents is discussed. In conclusion, theoretical contributions and practical implications of the study are presented.

\section{Related works}

\subsection{IT-based organizational creativity support}

An organization's success depends on its capability to create new knowledge that is then manifested in new, useful ideas and in innovations. Knowledge is an organization's most valuable resource because it embodies intangible assets, routines, and creative processes that are difficult to imitate. It is claimed that successful organizations are those that consistently create new knowledge, disseminate it widely throughout the organization, and rapidly include it in new products [4], [5].

One of the most cited definitions of organizational creativity says that the outcomes of organizational creativity are new and useful ideas that concern some products, services, processes, managerial practices as well as competitive strategies [6], [7], [8], [9]. Creativity is compared to information, knowledge [10], [11], [12] and knowledge system [13] used for solving different problems and increasing of organizational effectiveness [14]. Baron [15] compares creativity to creating something new from existing information and knowledge.

IT has become crucial for organizational success and has been the focus of a significant amount of recent organizational literature [4], [5]. However, to date there has been little research aimed at IT-based organizational creativity support. 
Davies et al. [16] state that creativity support systems (CSS) refer to fuzzily defined domains, having unknown requirements, with fuzzily defined measures of success, and are intended to support not precisely defined users, or their users behave in an unconventional way. Shneiderman [17] advocates that technologies "enable people to be more creative more often" are referred to as creativity support systems. Technically, the term CSS concerns a class of information systems encompassing diverse types of IS that share the enhancement of creativity [18]. It is pointed out that CSS may be used to: (1) enhance a user's ability to perform creative tasks (the ability that the user possesses already), (2) support users in domain knowledge acquisition, in order to free up their creativity, (3) give users new experiences concerning creative tasks, thus giving them new task-solving capabilities [19]. Shneiderman [17] argues that CSS should:

- offer indexes for work progress measurement, together with the possibility of generating alerts,

- contain libraries of images, thesauri, sketching interfaces, possibility of ideas mapping,

- support communication and collaboration, enable group work coordination,

- simplify knowledge coding in an electronic form. Muller and Ulrich [20] as well as Klijn and Tomic [7] argue that CSS may be used for:

- information collecting - by simplification of searching, browsing, and visualization,

- defining linkages between information,

- creative processes - by loose associations, examination of solutions, composing of artifacts, idea reviewing,

- disseminating the effects of creative cooperation.

Greene [21] states that organizational creativity support software should be able to: explore problem domain, teach and discover new problems, support collaboration, visualize domain interdependences as well as to simplify storing, classifying and mining of notions. Woodman et al. [22] point out that IT tools should enable first of all information flow and communication in an organization. Lubart [23], Ulrich and Mengiste [24] highlight the importance of "whatif" analyses, data and processes visualization, creative process' effects dissemination, visualization of ideas, human-computer dialogue in the problem solving process as well as advanced human-computer interaction, business plan support, and storing of users' preferences. In turn, Dewett [5] claims that three benefits appear to be particularly salient: the improved ability to link and enable employees, the improved ability to codify the organization's knowledge base, and improved boundary spanning capabilities. Some authors advocate that CSS stimulate users' imagination, the creation of new ideas, model creative processes as well as enable brainstorming process, recombination of ideas, ranging of ideas according to different criteria, and identification of interdependences [25].

Table I presents the most cited functions of IT for organizational creativity support.

Table 1. IT in organizational creativity support

\begin{tabular}{|l|l|}
\hline Functions of ICT & Authors \\
\hline $\begin{array}{l}\text { Information flow and communication } \\
\text { in an organization }\end{array}$ & {$[5],[22]$} \\
\hline $\begin{array}{l}\text { Collecting, storing, browsing and } \\
\text { analyzing of information, }\end{array}$ & {$[23],[25]$} \\
\hline $\begin{array}{l}\text { Exploring problem domain, } \\
\text { discovering of knowledge and } \\
\text { associations, learning, classifying of } \\
\text { notions }\end{array}$ & {$[21],[25]$} \\
\hline Visualization of information & {$[21],[23]$} \\
\hline Knowledge coding & {$[5],[17]$} \\
\hline Cooperation, work group & {$[5],[17]$} \\
\hline New problems discovering & {$[25]$} \\
\hline $\begin{array}{l}\text { Brainstorming, stimulation of users' } \\
\text { imagination, modeling of creative } \\
\text { processes }\end{array}$ & {$[19]$} \\
\hline $\begin{array}{l}\text { Creation of knowledge maps, thesaurus } \\
\text { and libraries }\end{array}$ & {$[17]$} \\
\hline Human-computer interaction & {$[23],[24]$} \\
\hline $\begin{array}{l}\text { Composing of artifacts, idea } \\
\text { reviewing, disseminating the effects of } \\
\text { creative cooperation }\end{array}$ & {$[7],[20]$,} \\
\hline
\end{tabular}

According to some scholars three types of CSS are distinguished [18, 26, 27, 28]: individual creativity support systems (ICSS), group creativity support systems (GCSS), and organizational creativity support systems (OCSS). The main purpose of ICSS is to increase the cognitive process, individual inspiration, as well as the learning and reasoning of individual persons. The most popular tools used in ICSS include: editors, visualization systems, brainstorming, e-mails, spreadsheets, databases and knowledge bases, scenarios, and modeling tools.

In turn, GCSS encompass several types of information systems, for example, group decision support systems, knowledge management systems, computer-mediated communication, which commonly supports the process of idea generation and idea evolution, and selection in groups. GCSS combines the properties of individual creativity support with collaboration and coordination support.

OCSS opens a new emerging group of creativity support. In contrast to previous systems, OCSS is dedicated to the whole organization and its 
environment. Its purpose is to increase competitive advantage and an organization's performance by offering rapid access to different, heterogeneous, dispersed information resources, their analysis, knowledge discovery, its visualization, and suggesting some opinions that may be the foundation for the creation of new and useful ideas.

The analysis of the relevant literature allows us to state that there is not a comprehensive view on organizational creativity support system and its design [4], [5]. A conceptual framework for the design of information systems to provide organizational creativity was not formulated and no attempt was made to validate it.

\subsection{Multi-agent approach}

The design of each information system should be based on proven theories and approaches. The multiagent approach gives a good foundation for the design of a new emerging concept - the organizational creativity support system - that is distinguished by a unique, intelligent construct, combining the features of different IT tools with various capabilities and resources.

The term "agent" is often associated with the following notions: intelligent agent, intelligent software, wizards, knowbots, taskbot, userbot, software agent, softbots-intelligent, or software robots. In a particular case the agent may be a human or an expert in the specific domain. According to Hewitt [29] an agent is an interactive object based on parallel processing, having some internal state, and the ability to respond to messages of other objects (actors). The agent is an entity that performs some actions in a particular environment and is aware of the emerging changes. Moreover, it can react to such changes [30], [31]. The agent has a set of goals, certain capabilities to perform actions, and some knowledge (or beliefs) about its environment [33], [34]. In addition, Thomsen [30] describes the agent as "a solution-oriented ensemble of capabilities including natural language processing, autonomous reasoning, proactive computing, discourse modeling, knowledge representation, action-oriented semantics, multimodal interaction, environmental awareness, self awareness, and distributed architectures". IBM [32], in turn, defines intelligent agents as "software entities that carry out some set of operations on behalf of a user or another program, with some degree of independence or autonomy, and in so doing, employ some knowledge or representation of user's goals and desires". Many authors emphasize the specific properties of the agents [30], [34], [35], [36]. They include: autonomy, reactivity, pro-activity, social ability, self-analysis, learning, temporally continuous, and mobile.
It has already been pointed out that its knowledge, its computing resources, and its perspective limit the capacity of an intelligent agent. Therefore, it requires forming communities (agency) of agents. These communities, based on a modular design, can be implemented, where each member of the agency specializes in solving a particular aspect of the problem. The agents must be able to interoperate and coordinate with each other in peer-to-peer interactions [31]. This idea of the agents' operation is nowadays described as a multi-agent system. A multi-agent system can be defined as a loosely coupled network of entities that work together to solve a problem that cannot be solved by an individual agent. These entities can show selforganization and complex behavior, even if the individual agent's strategies are simple [37]. A multiagent system is a network of agents that are reasoning (problem solvers) and cooperating, communicating, and negotiating to achieve a specific task. Individual agents are able to adapt their behavior to the changing environment in which they work [38], [39]. A good example of agents' co-operation is a teamwork in which a group of autonomous agents cooperate, both to develop their own individual goals as well as for the good of the whole system [40]. The following characteristics of multi-agent approach lead to the conclusion that such an approach can be widely used in the design of complex information systems for organizations. Particularly, it provides some extension and an alternative to organizational creativity support systems with flexible distributed, and intelligent features.

\section{Research method}

The main purpose of this study is to propose a comprehensive, conceptual framework for the design of information systems to provide IT-based organizational creativity support. To address the mentioned objective a multi-agent approach is used. A multi-agent approach is a critical and vital part of a theory for the design of organizational creativity support systems. Intelligent agents, as autonomous and proactive entities (software), are used to build assistance in performing various human activities, including: searching, collecting, analyzing data, discovering new knowledge, suggesting new idea, communicating and dissemination of new ideas, as well as conducting different interactions with human participants.

The proposed framework is distinguished by six stages. They refer to: (1) finding problems, (2) monitoring and acquiring information, (3) knowledge discovering and suggesting new ideas, (4) evaluating and selecting discovered knowledge/ideas, 
communicating newly discovered knowledge/ideas, and (6) evolving creative knowledge.

The proposed framework is used to build an organizational creativity support system (OCSS). OCSS consists of four groups of intelligent agents: (1) searching agents, (2) capturing agents, (3) monitoring agents, and (4) discovering and suggesting agents. Different techniques and tools are applied to develop such a system. They include mainly: web mining, text mining, web scraping, web opinion mining, neural networks, search engines, conceptual graphs, and visualization techniques.

\section{Findings and discussion}

The suggested framework provides a comprehensive view on the design of information systems to provide organizational creativity support. This framework consists of six stages that are strictly interconnected and are of interactive nature. They include:

1. Problem finding and identification of major creative needs of organizations.

2. Acquiring information resources.

3. Information analysis, knowledge discovery, providing some suggestions concerning new ideas.

4. Evaluating and selecting discovered knowledge.

5. Communicating newly discovered knowledge in an organization and considering whether the new knowledge should be transformed into innovation; and

6. Evolving creative knowledge in an organization, organizational learning.

\subsection{Problem finding}

Problem finding should be considered one of the most important steps in the whole model. It requires an organization/user to specify its creative needs, as well as some phrases, keywords (concerning its business areas, business problems to solve, etc.) that may be the foundation to find some problems. Various methods and techniques may be applied to better know the creative needs. They include the following: interviews, questionnaires, observations, and documentation analyses. Creative needs should be examined on the level of an individual, particular employee groups, and the whole organization along with its environment. This also involves analyzing closer and more remote environments. Both internal and external information resources may be the inspiration for problem finding. This implies some necessity to track not only business reports, documents and databases but also some public reports, scientific databases, patent collections, the Internet as well as to consider general trends on the market, activities undertaken by the competition, and to pay attention to comments from readers on on-line news [41]. It is really important to support problem finding, although this phenomenon is relatively underestimated in the relevant literature [5]. Some attention is paid to a possibility of decomposition, problem hierarchization, and creation of generalizations with the help of IT [42]. Intelligent agents, in an automatic, may replace humans in performing difficult, tedious, and time-consuming actions concerning searching and tracking various information resources. Agents may suggest as well as help detail (concretize and substantiate) the paths of problem finding, to create knowledge maps, and semantic maps. Agents themselves may specialize in searching specific sorts of information resources (e.g., social media, price comparison websites, patent catalogues, knowledge portals), communicate with each other, activate others agents to perform particular activities, and store the results of searching databases.

The result of this stage should be a list of terms, classes of terms, relationships between classes, and knowledge maps that facilitate the process of problem finding.

\subsection{Acquiring information resources}

The acquisition of information resources is one of the most difficult tasks to be undertaken in the whole model. This results from several factors, predominantly including the following:

- considerable dispersion and diversity of information resources,

- no access to numerous information resources,

- $\quad$ poor quality of data in different repositories (e.g., incoherence, inconsistent).

This stage involves some ability to reach diversified resources of information (identified in the first stage) and to absorb new resources of knowledge. This calls for the exploration of both internal and external resources (indicated at the problem finding stage). The former may include: paper files, documents that describe the enterprise's mission and strategy of development, selected sales documents, financial documents, enterprise resource planning systems, databases, data warehouses, Business Intelligence systems, customer relationship management systems, supply chain management systems, decision support systems, and case history. Organizational creativity more and more frequently requires acquisition of information that stems from external resources [4]. Such resources may include databases of patents, company reports, government records, library archives, scientific databases, and Internet resources including social media, blogs, and comparison websites. However, it is necessary to remember the imperfection 
of the human memory that is characterized by limited capability of storing different information. IT enables coding huge amounts of diversified information that gets compared with organizational memory, but also quick browsing, analyzing, and discovering new knowledge. In this context, impressive capacities are offered by databases, knowledge bases, data warehouses, in-memory applications, and knowledge portals [43]. Analogous to the first stage of the proposed framework, intelligent agents may be incorporated in accomplishment of tedious and timeconsuming tasks that concern acquiring, monitoring, and browsing huge amount of information. Agents may quickly react to some changes in information content, promptly answers the perceived changes, and store the acquired information in databases. These databases may be analyzed later in detail and filtered. A result of this stage of the proposed framework should be the establishment of a repository that enables storage of up-to-date, reliable, complete, and relevant information useful while looking for new ideas.

\subsection{Information analysis, knowledge discovery,} providing some suggestions concerning new ideas

The third step of the proposed framework involves the analysis and discovery of new knowledge. Different IT tools may support analyzing and generating new knowledge. Data mining, artificial intelligence, and data visualization techniques are a very important group of IT tools in knowledge discovery [43], [44], [45]. These tools allow for exploring different sources of data, identifying specific relationships and interdependencies [46]. They may point, for example, to different trends that are observed on the market, customer behaviors or customer purchase preferences. On the other hand, data visualisation techniques enable perception and understanding of all interdependencies between different data. It is also worth mentioning group work tools that may be used to discover new knowledge. These tools show that creativity is not obtained in social isolation. Individuals and groups continuously participate in creative and interactive processes. Employees create knowledge, present it to other members of their teams, and learn from others in order to eventually modify and enhance their primary ideas. Group work tools allow members of project teams to communicate easily, thus overcoming barriers of time and geographical location. People may work in networks and use joint resources.

At this stage, agents can contribute to the growth and expansion of knowledge. By applying various methods and techniques of artificial intelligence they enable, in an automatic way, the search of some associations and patterns between data, and then suggest some recommendations concerning new ideas. By combining the resources of large databases with intelligent agents, organizations may be able to learn valuable facts from data.

\subsection{Evaluating and selecting discovered knowledge}

Organizational creativity is an iterative process full of attempts and mistakes [5]. Hence, the process in question requires control, evaluation and selection of the analyzed information/discovered knowledge, and the best suggestions from the whole pool of the ones generated. Knowledge portals, visualization tools and group work tools (including virtual conferences, discussion forums, and communities of practice) may turn out to be useful for evaluation, analysis of collected information, and new discovered knowledge [26]. Group work tools allow members of project teams to communicate easily, work in networks, discuss, compare obtained results (new ideas), and evaluate them. Visualization tools enable better perception, understanding and evaluation of newly discovered knowledge. Intelligent agents may provide different documents and reports needed to evaluate new ideas. Additionally, they may be used to initiate interactions with participants.

\subsection{Communicating newly discovered knowledge in an organization and considering whether the new knowledge should be transformed into innovation}

Communicating new knowledge and deciding whether it should be transformed into innovation make up, in principle, the final stage of the whole model. Such communication should reach all potential departments involved (production, marketing, customer service, etc.) and individuals who might be interested in its utilisation. IT, including intelligent agents, are becoming a channel to be used by new knowledge/ideas and organisational creativity objectives while being distributed all over the organisation affected. Intelligent agents allow for easier rooting of creativity in organisational culture. They may facilitate values, beliefs, and standards because they allow for quick transmission of different information to a group of people. Intelligent agents can be incorporated in knowledge portals, intranets, information bulletins, newsletters or employee forums, initiating various discussions and forums between them.

\subsection{Evolving creative knowledge in an organization and organizational learning}

The last stage of the proposed framework pays some attention to the fact that organisational creativity is not a closed cycle but a continuous and dynamic process that should lead to the development of creative knowledge in any organisation. This completes the 
generation of one piece of knowledge but simultaneously attempts to integrate knowledge that comes from different research domains. Intelligent agents may provide access to different databases and portals as well as combine resources from various research domains.

\subsection{A design of organizational creativity support system}

In this section, the system called organizational creativity support system (OCSS) was presented as an example of the proposed framework being applied. The area of consumer electronics was chosen to illustrate how intelligent agents may be used to build such a system as well as how organizations from this sector, may draw inspiration to improve its products and services through in-depth analysis of consumer opinion.

Consumer electronics (smartphones, tablets, laptops, cameras etc.) is one of the most dynamic sectors on the global market. Organizations that want to survive on this market and become a leader should respond quickly to feedback. According to Boston Consulting Group [47], Polish Internet users are one of the most active groups of consumers in Europe. It is demonstrated not only by the quantity of products bought by Polish consumers (mobile phones, laptops, digital cameras and other gadgets, etc.), but also by their activity in discussion forums, where they express their opinions on the products purchased, compare them to competitors, or even propose some ideas related to their improvement. Ceneo.pl is one of the largest forums in Poland where consumers report their opinions on the products they buy.

When designing an OCSS, it was assumed that it should be flexible enough to allow: (1) automatic searching and monitoring of various information resources (internal resources and external resources like: the Internet, social media), according to specific phrases and keywords in order to find particular problems in the domain of consumer electronics, (2) automatic acquisition of various data originating from different, dispersed, heterogeneous resources that may be helpful in searching new ideas concerning new products from consumer electronics, (3) automatic analyzing and discovering new knowledge (e.g., discovery of new product features), (4) automatic visualization of discovered knowledge (e.g., correlations among product features and consumer opinions), (5) automatic suggesting/recommending (e.g., what product features should be primarily improved, changed or what features should be removed), (6) automatic delivery of new knowledge to users, who based on their own knowledge and experience, make-decisions on how it finally may be used, (7) storing of collected, and analyzed knowledge to use by different users.

Four main sorts of agents are incorporated into OCSS (Figure 1). They include:

- searching agents,

- monitoring agents,

- capturing agents,

- discovering and suggesting agents.

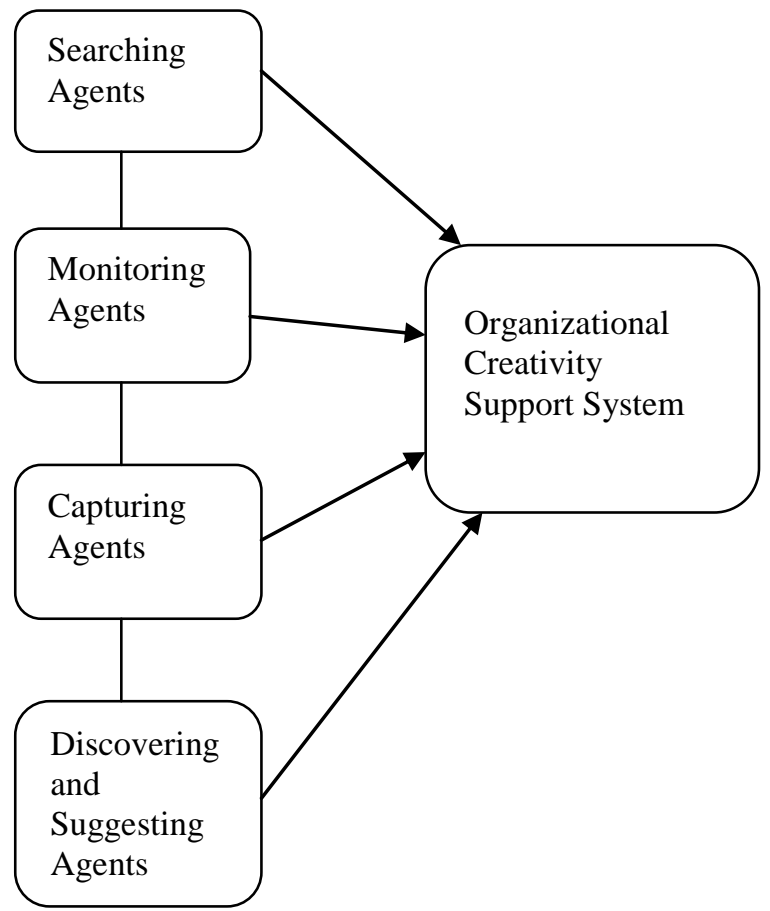

Figure 1. Organizational creativity support
system as a set of different agents

These agents, attributed with functions, rules, and methods to work in the specific domain, are autonomous entities. They may work independently or collaborate with other agents and users. Additionally, a manager agent is responsible for the reliability of the whole system and manages the operation of the individual agents.

\subsubsection{Searching agents}

As has been pointed out, organizations from the sector of consumer electronics in search of new problems and ideas should explore not only own, internal information resources but more and more their interest should focus on external resources (e.g., public data bases, patent bases, the Internet, social media). The Internet and social media are places where customers express their opinions about various products (smartphones, tablets, etc.). Such opinions may be helpful in finding new designs, product functions, and solving a specific organization's 
problems. Problem finding in OCSS is assisted mainly by searching agents. Searching agents, in an automatic way, perform tedious, time-consuming operations that concern searching huge amount of information. Users, giving particular key words and phrases that refer to the issue of consumer electronics (e.g., smartphone) obtain the list of relevant and adequate databases, papers, patent collections, links, and web sites. Searching agents support finding new information resources, indentifying their origin, access, and credibility.

\subsubsection{Capturing and monitoring agents}

There are two groups of agents to acquire information resources. They include capturing and monitoring agents. The task of capturing agents is to search and collect important information about: features of the products and their characteristics, product characteristics of the competitors; characteristics of the user's activity, characteristics of the competitor's activity, characteristics of others users (customer, suppliers) relating to: the date and time of the activity detection, area of activity; status, and the date and time of the capturing agents' activation. They mostly acquire certain keywords, different phrases ("positive", "negative") or files. A user is provided with an application that allows for clicking a "Run Agents" button to initiate the capturing agent manually any time it is required. A user may quickly and intuitively download from the website information that represent the customers' opinions concerning given products.

Monitoring agents are used to track the changes in opinions of the users on some smartphones in selected social media or price comparison websites. When the agent detects new content (e.g., new features of such product, new opinions on such product) posted in the price comparison website or in social media, it sends a signal that activates the capturing agent. This group of agents includes agents that monitor changes on: (1) the opinions on some organization's products and services (features, quality), (2) the opinions on some products of the competition, and (3) the opinions of the users (including customers and suppliers) of the other products. Information collected by individual capturing agents are stored in CSV, SQL, XML, XLS files and then are loaded to a database - called opinion storage. Then, such data is processed and analyzed by discovering \& suggesting agents.

\subsubsection{Discovering and suggesting agents}

Discovering and suggesting agents are responsible for performing various analyzes and discovering new knowledge that refer to the opinions of users, customers and competitors on selected products. More precisely speaking, they: (1) identify features of the selected smartphones and link (associate) these features with the opinions of various customers, (2) carry out analysis on products and perform appropriate analysis focused, for example, on improving some features, (3) suggest some recommendations concerning changes/modifications to product features, (4) draw up the characteristics of the customers (users activity, changes in preferences).

To make the conducted analysis more clear and intuitive for users, different visualization techniques were applied. Graph structures are useful methods to visualize data. In order to construct a graph structure, NetworkX 1.8.1 library was used [48]. Graph clustering was performed with the usage of the ForceAtlas2 algorithm that is available in the Gephi package [49, 50, 51]. All operations involving data processing were performed in the Python 2.7 environment.

Graph structures made the conducted analysis more intuitive and visualized object-feature relationships (Figure 2).

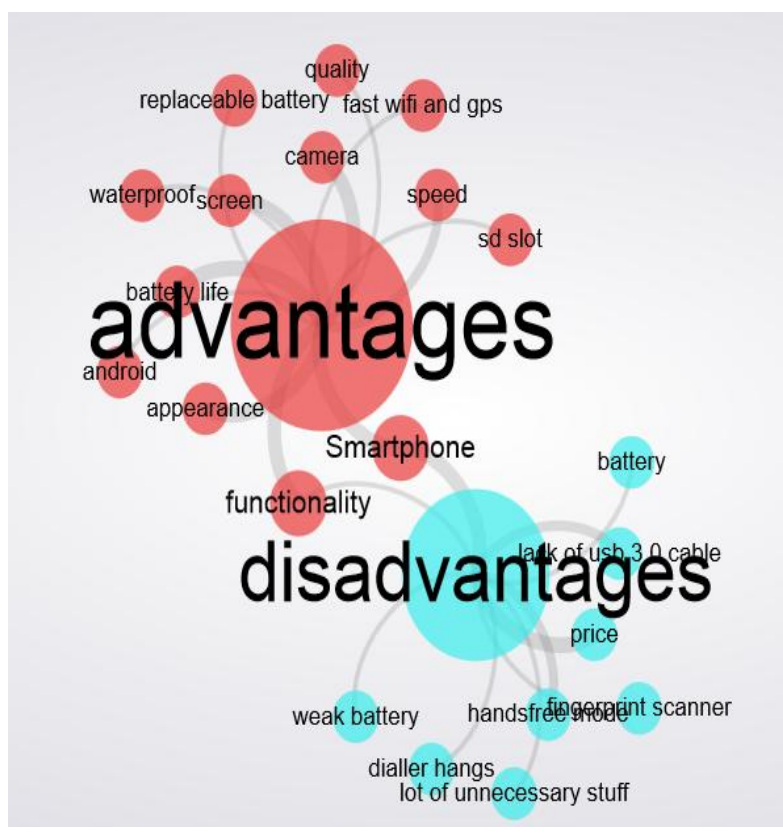

Figure 2. Visualization of the relationship between the features of the selected product and the users' opinions ("positive","negative")

A graph always has three major vertices (nodes): a node that defines the product, a node that refers to advantages, and a node that refers to disadvantages. Other nodes refer to terms that describe a product. Graph edges have their own weights. Weights of connections in the graph mean the frequency a particular term appears. The more frequently appearing the feature, the higher weight of the connection with a 
node of advantages or disadvantages. The visualization presented employs colours to distinguish features attributed to objects. Each colour allows for classifying a particular node to a given class of objects, e.g., in this case advantages or disadvantages. Valuable information for a user is also provided by the size of 'advantages' or 'disadvantages' nodes. The size allows for quick assessment to find out if a particular object is connected with more positive or negative feedback.

Many inspirations for the product development/improvement may be provided by the analysis of comparing various products together (e.g., competitive products and even products from different segments). Figure 3 shows a graph where the nodes are described by the names of various products (e.g., competitive products) and associated with these products, the customer opinions. The edges illustrate the relationship of the products with customer feedback. A characteristic feature of this analysis is the presence of a large number of products with universal features (the central part of the graph - price, portable, stylish, fast) and products with unique characteristics prevailing (fingerprint scanner, HD video, extra security- the outskirts of the graph). In the present case, it is difficult to indicate what specific links exist between the various products. The identification of such relationships is, however, essential when comparing the product with other products. These characteristics may be unique (not found in other product). There may also be a reverse situation - they can be commonly found in other products.

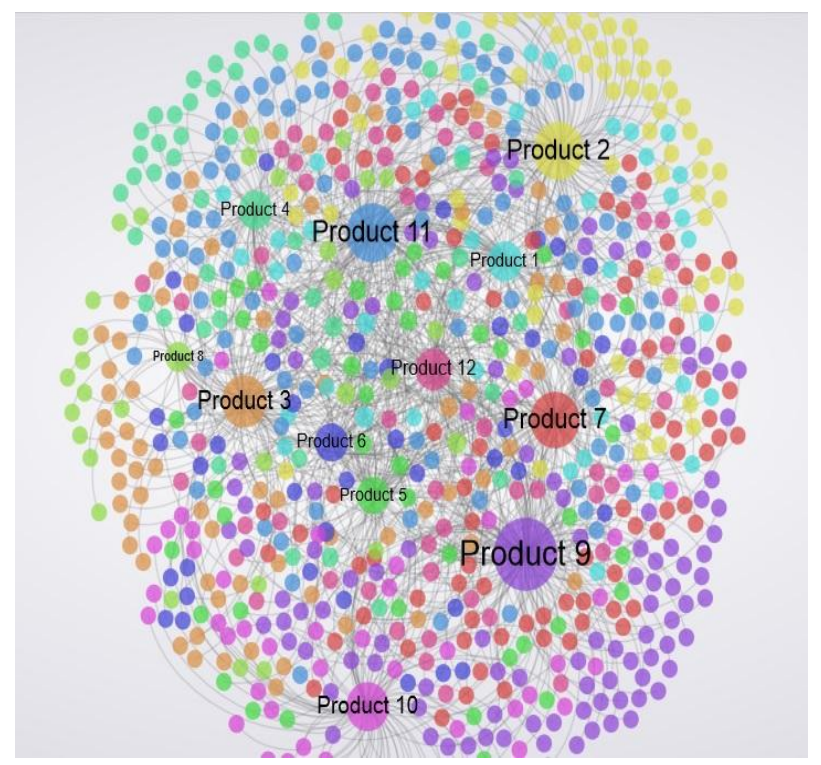

Figure 3. Example of data visualization

Finally, newly discovered knowledge, its visualization and some suggestions (e.g., concerning improving some products, introducing new features, new functionalities), performed by OCSS, are stored in a database - called storage. Such collected knowledge, as well as the knowledge and experience of the user, may be the foundation to generate new ideas and then innovations.

Discovered knowledge is mapped and presented in a knowledge portal. A knowledge portal is a space that some news (e.g., about innovations, business plans) and business activities are discussed, shared, and evaluated by managers, employees and others users. Discussion forums, wiki, document management systems, intranets, and extranets are the main components of such a portal. Intelligent agents in a knowledge portal contribute not only to exchanging knowledge but also to combining new knowledge with already existing knowledge or replacing already existing knowledge with new knowledge.

Summing up, the initial testing of OCSS has proven that such system is able to support mainly: (1) tracking and acquiring of information from various social media (price comparison websites), (2) discovering new knowledge (e.g., some patterns, correlations among selected products and consumer opinions), (3) suggesting some ideas and changes (e.g., in product development/improvement), (4) disseminating and exchanging new knowledge. OCSS provides the organization with relevant information (directly from customers, suppliers, competitors) about their opinions, interests and preferences. Such information may be useful in the evaluation of a product's market position and in the determination of the direction of its further development. It may thus be important for the marketing department, promotion, or research and development department, in the search for new and more attractive products.

\section{Conclusions}

Our study attempts to formulate a new, comprehensive framework for information system design to support organizational creativity. It consists of six stages that include: (1) problem finding, (2) acquiring information resources, (3) information analysis, knowledge discovery, providing some suggestions concerning new ideas, (4) evaluating and selecting discovered knowledge/ideas, (5) communicating newly discovered knowledge in an organisation and considering whether the new knowledge should be transformed into innovation, and (6) evolving creative knowledge in an organisation and organizational learning.

The proposed framework was applied and initially tested in a social media environment. As a result OCSS was built. Customer opinions from the consumer electronic sector were the center of the analysis. The 
system consists of four types of agents. They assist and help perform various activities that concern mainly acquiring, analyzing, discovering new knowledge and suggesting some recommendations concerning new and useful ideas. Agents are also able to communicate with each other, exchange knowledge and initiate communication with human participants.

Our study makes several theoretical contributions to the relevant literature: (1) it contributes to the emerging literature on organizational creativity by investigating the issue of the design of information system to support organizational creativity, (2) it proposes a comprehensive, conceptual framework for the design of an information system to provide organizational creativity support, (3) it demonstrates how IT and a multi-agent approach may be applied to support various human activities and tasks.

The obtained findings and outcomes of this study should be useful for any designers of information systems as well as mangers and organizations willing to use organizational creativity support systems.

\section{Acknowledgments}

This paper has been supported by a grant: "Methodology for Computer Supported Organizational Creativity" from the National Science Centre in Poland, 2013/09B/HS4/00473.

\section{References}

[1] K.D. Elsbach and A.B. Hargadon, "Enhancing creativity through "mindless" work: A framework of work day design", Organization Science, vol. 17, pp. 470-483, 2006.

[2] J. A. McLean, "Place for creativity in management", The British Journal of Administrative Management, pp. 30-31, Autumn, 2009.

[3] S. J. Shin and J. Zhou, "When is educational specialization heterogeneity related to creativity in research and development teams? Transformational leadership as moderator", Journal of Applied Psychology, vol. 92, pp. 1709-1721, 2007.

[4] R.B. Cooper, "Information technology development creativity: A case study of attempted radical change", MIS Quarterly, vol. 24, no. 2, pp. 245-276, 2000.

[5] T. Dewett, "Understanding the relationship between information technology and creativity in organizations", Creativity Research Journal, vol. 15, no. 2-3, pp. 167-182, 2003.

[6] Y.P. Gong, J.C. Huang, and J.L. Farh, "Employee learning orientation, transformational leadership, and employee creativity: The mediating role of creative self-efficacy", Academy of Management Journal, vol. 52, pp. 765-778, 2009.
[7] M. Klijn, W. Tomic, "A review of creativity within organizations from a psychological perspective", Journal of Management Development, vol. 29, pp. 322343, 2010

[8] W. Choi, N. Madjar, and Y. Yun, "Perceived organizational support, goal orientation, Exchange ideology and creativity", Proceedings of Academy of Management, Montreal, 2010.

[9] J. Zhou, R. Ren, "Striving for creativity. Building positive contexts in the workplace", in The Oxford Handbook of Positive Scholarship, K.S. Cameron and G.M. Spreitzer, Ed. Oxford/New York: Oxford Press, pp. 97-109, 2010.

[10] P. Drucker, Innovation and entrepreneurship. New York: NJ: Routledge, 2014.

[11] T.H. Davenport, Thinking for a Living: How to get better performance and results from knowledge workers. Boston-Massachusetts: Harvard Business School Press, 2005.

[12] T.M. Amabile, "A model of creativity and innovation in organizations", Research in Organizational Behavior, vol. 10, pp. 123-167, 1988.

[13] M. Basadur, T. Basadur, and G. Licina, "Organizational development", in Handbook of organizational creativity, M.D. Mumford, Ed. London: Academic Press/Elsevier, pp. 667-703, 2012.

[14] J.D. Houghton and T.C. DiLiello, "Leadership development: The key to unlocking individual creativity in organizations", Leadership \& Organization Development Journal, vol. 11, pp. 230245, 2010

[15] R.A. Baron, Entrepreneurship. An evidence-based guide. Cheltenham: Edward Elgar, 2012.

[16] N. Davies, A. Zook, B, O'Neill, B. Headrick, M. Riedl, A. Grosz, and M. Nitsche, "Creativity Support for Novice Digital Filmmaking", in Proceedings of the SIGCHI conference 2013, Paris, New York: ACM, pp. 651-660, 2013.

[17] B. Shneiderman, "Creativity Support Tools: Accelerating Discovery and Innovation", Communications of the ACM, vol. 50, no. 12, pp. 2032, 2007.

[18] M. Voigt and K. Bergener, "Enhancing creativity in groups - proposition of and integrated framework for designing group creativity support systems", in Proceedings of 46th Hawaii International Conference on System Sciences, IEEE Computer Society, pp. 225234, 2013.

[19] K. Nakakoji, "Meanings of Tools, Support, and Uses for Creative Design Processes", CREDITS Research Center: International Design Research Symposium'06, Seoul, pp. 156-165, 2006,.

[20] S. D. Muller and F. Ulrich, "Creativity and Information Systems in a Hypercompetitive Environment: A Literature Review", Communications of the Association for Information Systems (CAIS), vol. 32, no. 1, pp. 175-201, 2013.

[21] S. Greene, "Characteristics of applications that support creativity", Communications of the ACM, vol. 45, no. 10, pp. 100-104, 2002. 
[22] R. W. Woodman, J.E. Sawyer, and R.W. Griffin, "Toward a theory of organizational creativity", Academy of Management Review, vol. 18, no. 2, pp. 293-276, 1993.

[23] T. Lubart, "How can computers be partners in the creative process: classification and commentary on the special issue", International Journal of HumanComputer Studies, vol. 63, no. 4-5, pp. 365-369, 2005.

[24] F. Ulrich and S. Mengiste, "The Challenges of Creativity in Software Organizations", in Creating Value for All Through IT, B. Bergvall-Kareborn and P. Nielsen, Ed. Berlin Heidelberg: Springer, pp. 16-34, 2014.

[25] B. Indurkhya, "On the role of computers in creativitysupport systems", in Looking into the Future of Creativity and Decision Support Systems, A. Skulimowski, Ed. Kraków: Progress \& Business Publishers, pp. 233-244, 2013.

[26] J.F. Nunamaker, R.O. Briggs, and D.D. Mittleman, "Lessons from a decade of group support system research", in Proceedings of 28th Hawaii International Conference on System Sciences, IEEE Computer Society, 1996.

[27] M. Voigt, B. Niehaves, and J. Becker, "Towards a Unified Design Theory for Creativity Support Systems", in DESRIST, K. Peffers, M. Rothenberger, and B. Kuechel, Ed. Berlin Heidelberg: SpringerVerlag, pp. 152-173, 2012.

[28] T. Heweet, M. Czerwinski, M. Terry, J. F. Nunamaker, L. Candy, B. Kules, and E. Sylvan, "Creativity Support Tools Evaluation Methods and Metrics", in Creativity Support Tools, A workshop sponsored by the National Science Foundation, Washington, June 13-15, 2005, retrieved from http://www.cs.umd.edu.hcil/CST

[29] C. Hewitt, "Viewing Control Structures as Patterns of Passing Messages", Artificial Intelligence, vol. 8, no. 3, pp. 323-364, 1977.

[30] E. Thomsen, "Agents uncovered", Intelligent Enterprise, vol. 5, no. 15, pp. 45, 2002.

[31] I. Rudowsky, "Intelligent agents", in Proceedings of the Americas Conference on Information Systems, New York, 2004.

[32] IBM's Intelligent Agent Strategy, white paper, retrieved

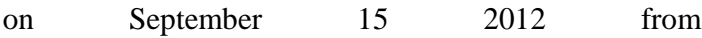
http://activist.gpl.ibm.com:81/White Paper/ptc2.htm.

[33] M. Wooldridge, An Introduction to Multi Agent Systems. New York: John Wiley and Sons Ltd., 2009.

[34] L.Sterling and K. Taveter, The Art of Agent-Oriented Modeling. Cambridge, London: The MIT Press, 2010.

[35] C.M. Olszak and T. Bartuś, "Multi-Agent Framework for Social Customer Relationship Management Systems", in Issues in Informing Science and Information Technology, E. Cohen, Ed. Santa Rosa: Informing Science Institute, vol. 10, pp. 368-387, 2013.

[36] F. Bellifemine, G. Caire, and D. Greenwood, Developing Multi-agent Systems with JADE. Chichester: John Wiley and Sons Ltd., 2007.

[37] A. Bologa and R. Bologa, "Business Intelligence using Software Agents", Database Systems Journal, vol. 2, no. 4, pp. 31-42, 2011.
[38] D. Weyns, Architecture-Based Design of Multi-Agent Systems. Berlin Heidelberg: Springer-Verlag, 2010.

[39] R. Bordini, J. Hübner, and M.Wooldridge, Programming Multi-Agent Systems in AgentSpeak using Jason. New York: John Wiley and Sons Ltd., 2007.

[40] V. Lesser, S. Abdallah, "Multiagent Reinforcement Learning and Self-Organization in a Network of Agents", AAMAS 07, Honolulu, Hawaii, ACM, 2007.

[41] L. Qian, Z. Mi, and Z. Xin, "Understanding News 2.0: A framework for explaining the number of comments from readers on online news", Information \& Management, vol. 52, issue 7, pp. 764-776, 2015.

[42] H. Coskun, P.B, Paulus, V. Brown, and J.J. Sherwood, "Cognitive stimulation and problem presentation in idea-generating groups", Group Dynamics: Theory, Research, and Practice, vol. 4, no. 4, pp. 307-329, 2000.

[43] H. Chen, R.H.L. Chiang, and V.C. Storey, "Business Intelligence and analytics: from Big data to big impact", MIS Quarterly, vol. 36, no. 4, pp. 1-24, 2012.

[44] J. Han, M. Kamber and J. Pei, Data Mining. Concept and Technique., New York: Morgan Kaufmann, 2011.

[45] C.M. Olszak, "Toward better understanding and use of Business Intelligence in organizations", Information Systems Management, vol.33, no. 2,pp. 105-123, 2016

[46] D.T. Larose, Discovering Knowledge in Data. An Introduction to Data Mining. New York: John Wiley \& Sons, Inc., 2005.

[47] Polska Internetowa. Jak internet dokonuje transformacji polskiej gospodarki, The Boston Consluting Group, retrieved April 152015 from http://www.polskainternetowa.pl/pdf/raport_BCG_pols ka_internetowa.pdf.

[48] networkx.github.io, retrieved January 102015 from https://github.com/networkx/.

[49] gephi.github.io/toolkit, retrieved January 102015 from https://github.com/gephi/gephi-toolkit.

[50] M. Jacomy, T. Venturini, S. Heymann, and M. Bastian, "ForceAtlas2, aContinous Graph Layout Algorithm for Handy Network Visualisation for the Gephi Software", PLoS ONE, vol. 9, no. 6, 2014, retrieved January 10 2015 from http://journals.plos.org/plosone/article?id=10.1371/jour nal.pone.0098679.

[51] M. Bastian, S. Heymann, and M. Jacomy, "Gephi: an open source software for exploring and manipulating networks", International AAAI Conference on Weblogs and Social Media, 2009, gephi.github.io. 